\title{
Formalismo e reforma do Estado: Um estudo de caso em um Tribunal do Poder Judiciário Federal
}

\author{
Formalism and state reform: A case study in a judicial power of the \\ federal court
}

Valéria Aparecida Antunes Freitas Vargens ${ }^{\mathrm{I}}$ Diogo Henrique Helal $^{2}$

\section{Resumo}

Esta pesquisa objetiva analisar como se dá a relação entre o formalismo e a execução da reforma do estado no Poder Judiciário, na ótica dos servidores de um Tribunal Federal do país. Como estudar a reforma em um órgão do Poder Judiciário Federal bastante complexo é tarefa ampla, restringe-se aqui o enfoque, ao Regime Jurídico Único dos Servidores Públicos - Lei 8.112/90 - e suas alterações. Utilizou-se o estudo de caso descritivo, de caráter qualitativo. A análise dos resultados permite afirmar que houve influência da administração patrimonialista, burocrática e gerencial na implementação da reforma, além da presença de traços formalísticos na administração. O modelo híbrido de administração é percebido pela combinação de traços paternalistas, corporativistas, burocráticos e até mesmo gerencial que prevalece nos gestores do tribunal pesquisado.

Palavras-chave: Formalismo; Reforma do Estado; Estudo de Caso.

\begin{abstract}
This research aims to analyze how works the relationship between the formalism and Judiciary State reform implementation, in the view of servers in a country Federal Court. As to study the reform of a complex agency of the federal Judiciary Power is a wide task, the focus here is restricted, to the Public Servants Single Legal Regime - Law 8.112/90 - and its amendments. The results analysis suggests that there was influence of patrimonial administration, bureaucratic and managerial in the reform implementation, and the presence of formalistic traces in the administration.
\end{abstract}

Keyword: Formalism; State Reform; Case Study.

\footnotetext{
1 vvargens@hotmail.com, Brasil. Professora da Faculdades Integradas Pitágoras - FIP. Mestre em Administração pela Faculdade Novos Horizontes - FNH. Rua Alvarenga Peixoto, 1270, Santo Agostinho, CEP: 30180-121 - Belo Horizonte, MG - Brasil.

2 diogohh@yahoo.com.br, Brasil. Professor Adjunto da Universidade Federal da Paraíba - UFPB. Doutor em Ciências Humanas: Sociologia e Política pela Universidade Federal de Minas Gerais - UFMG. Rua Alvarenga Peixoto, 1270, Santo Agostinho, CEP: 30180-121 - Belo Horizonte, MG - Brasil.
}

Recebido em 07.11.2012

Aprovado em 10.02.2013 


\section{Introdução}

Na busca por modelos de administração do Estado brasileiro, o País passou por três reformas: a primeira, em I936, conhecida como "Reforma burocrática"; a segunda, em I967, um ensaio de descentralização e de desburocratização; a terceira, em 1995 , apresentou e buscou implementar uma administração pública gerencial, como resposta à crise dos anos de I980 e à globalização da economia. (BRESSER PEREIRA; SPINK, 2005).

Para Faoro (2000), o Estado e a Administração Pública no país têm origem no patrimonialismo como marca perceptível de uma ética, cuja expressão maior se dá a partir da apropriação da esfera pública pela privada, especialmente, nas práticas administrativas e estamentais.

A partir do século XIX, o surgimento do capitalismo industrial e das democracias parlamentares trouxeram a necessidade de maior estabilidade e racionalidade na atuação do Estado. Fez-se necessária, assim, uma administração que distinguisse o público do privado e, também, o político e o administrador. Surgiu, então, a administração burocrática moderna racional-legal, que se preocupa com o cumprimento de leis como forma de combater a corrupção e o nepotismo patrimonialista. A grande expectativa em torno desse modelo refere-se ao controle da ação governamental, impedindo que políticos ajam contra os interesses coletivos da comunidade. Entretanto, a tentativa de tudo controlar na Administração Pública fez com os resultados da ação do Estado fossem deixados em um segundo plano. (ABRÚCIO, 2005).A Administração Pública gerencial apresenta-se como resposta à expansão das funções econômicas e sociais do Estado, ao desenvolvimento tecnológico e à globalização da economia mundial. Na década de I980, logo após a eclosão da crise de endividamento internacional, parte dos Estados se voltou para a reforma e para o ajuste fiscal. A Administração Pública Gerencial ganhou força como resposta à crise do Estado para enfrentar a crise fiscal, sendo também uma estratégia para reduzir o custo e tornar mais eficiente a administração dos imensos serviços que cabiam ao Estado e como instrumento de proteção do patrimônio público contra os interesses do "rent-seeking", ou da "corrupção aberta" (BRESSER PEREIRA; SPINK, 2005, p. 28). 
Apesar dessas experiências, identifica-se ainda na administração pública nacional um hibridismo dos três modelos de administração - Patrimonialista, Burocrático e Gerencial - decorrente da dificuldade em se abandonar valores e práticas tradicionais na esfera pública. Trata-se, sem dúvida, de uma tarefa bastante difícil, em face do caráter formalista do Estado e da sociedade nacional. Entende-se por formalismo a “discrepância entre a conduta concreta e a norma prescrita que se supõe regulá-la" (GUERREIRO RAMOS, I966; I983). Ocorre quando o comportamento efetivo das pessoas não observa as normas estabelecidas.

Nesse cenário, cabe aos gestores da justiça federal aplicar as leis aprovadas com a reforma do Estado, no âmbito do Tribunal, sem privilégios ou intervenções, uma vez que o objetivo da reforma do Estado é a sua organização e o abandono de visões do passado de um Estado assistencialista e paternalista (CARDOSO, 2005; BRESSER PEREIRA, $2005)$.

Por meio do instrumento burocrático legal - neste caso, as alterações no regime jurídico único dos servidores públicos, Lei 8.II2/90 -, o PDRE objetiva pôr fim ao patrimonialismo e à centralização das decisões, tornando a administração mais eficiente e moderna.

Sabe-se que a reforma do Estado de 1995 e sua implementação nas diversas áreas e setores das organizações públicas nacionais é objeto de pesquisa de vários autores (e.g. DINIZ, I998; ABRÚCIO, 2005; COSTA, 2008b; MATIAS-PEREIRA, 2008). Em particular, esta pesquisa objetiva analisar como se dá a relação entre o formalismo e a execução da reforma do estado no Poder Judiciário, na ótica dos servidores de um Tribunal Regional Eleitoral do país. Como estudar a reforma em um órgão do Poder Judiciário Federal bastante complexo é tarefa ampla, restringe-se aqui o enfoque, ao se tratar da reforma do Estado, ao Regime Jurídico Único dos Servidores Públicos - Lei 8.II2/9o - e suas alterações. Dado que esse marco legal trouxe grandes consequências para os servidores, estudar as opiniões e impressões dos envolvidos no Tribunal constitui-se em tarefa necessária.

\section{Modelos de Administração Pública}

A Administração Pública no Brasil é caracterizada por diversos elementos e 
dimensões herdados das crenças e práticas provenientes da formação social e histórica do país, que manifestam traços peculiares que prevalecem no modelo de gestão pública. Nunes (1997) considera que ela é marcada pelo hibridismo nas relações entre Estado e sociedade, ou seja, pela convivência de diversos tipos de gramática, como o personalismo e o impersonalismo.

\section{Administração Pública patrimonialista}

A Administração Pública Patrimonialista é caracterizada, dentre outros aspectos, pela apropriação do público pelo privado. Nela, os cargos públicos são distribuídos entre os parentes como se fossem de posse particular, predominando o nepotismo, o empreguismo e a corrupção.

O patrimonialismo é caracterizado como forma de dominação tradicional, em que o soberano organiza o poder político análogo ao poder exercido em sua casa. Para Weber (2004), na dominação patriarcal as normas baseiam-se na tradição, no costume; nela, é a submissão pessoal ao senhor que garante a legitimidade das regras por este estatuídas. Weber destaca ainda que ao cargo patrimonial falta, sobretudo, a distinção burocrática entre a esfera "privada” e a “oficial”. Holanda (2006, p.I46) comenta que "é possível acompanhar, ao longo da história brasileira, o predomínio constante das vontades particulares, que encontram seu ambiente próprio em círculos fechados e pouco acessíveis a uma ordenação impessoal”.

O personalismo do brasileiro atinge também as esferas política e jurídica. As campanhas eleitorais costumam se apoiar na imagem de um determinado "patriarca" da região. O povo não vota no partido ou no candidato pelo seu histórico político, mas na figura que representa o partido. Em algumas regiões, pratica-se, até hoje, o famoso "voto de cabresto", quando o coronel diz aos seus súditos em quem votar. De acordo com Matias-Pereira (2008), o Estado patrimonialista está fortemente presente na cultura política brasileira e se manifesta no clientelismo, no fisiologismo e na corrupção.

Para Freitas (1997), a família patriarcal forneceu o modelo moral que regula as relações entre governantes e governados, definindo as normas de dominação, que centraliza o poder nas mãos dos governantes e mantém a subordinação dos governados. Nesse sentido, a influência da família patriarcal e do sistema agrário na questão 
hierárquica predomina até hoje nas empresas privadas e na Administração Pública.

\section{Administração Pública burocrática}

O advento do capitalismo e da democracia trouxe a necessidade da adoção de um novo modelo capaz de combater as práticas patrimonialistas e de proteger o patrimônio público contra a privatização do Estado. A Administração Pública burocrática apareceu com o propósito de conseguir controlar o conteúdo da ação governamental, impedindo que os políticos ajam contra os interesses coletivos da comunidade (BRESSER PEREIRA, 2005).

Tal modelo ganhou força no Brasil, na década de I930, por meio da criação do Departamento Administrativo do Serviço Público (DASP), cujo propósito era constituirse em um agente modernizador dos processos administrativos, de acordo com o modelo burocrático, promovendo a racionalidade e a eficiência do Estado. Além disso, objetivava implantar critérios profissionais para o ingresso, a promoção e o desenvolvimento da carreira no serviço público, mediante formação de uma política de administração de pessoal baseada no mérito, supervisionar a Administração Pública e fixar o orçamento nacional vinculado ao planejamento (PDRAE, I995).

Bresser Pereira (1996) explica que a criação do Departamento Administrativo do Serviço Público (DASP) representou não apenas a primeira reforma administrativa do País, com a implantação da Administração Pública burocrática, mas também a afirmação dos princípios centralizadores e hierárquicos da burocracia clássica.

A reforma administrativa do Estado Novo constituiu-se, assim, no primeiro esforço sistemático de superação do patrimonialismo. Foi uma ação deliberada e ambiciosa no sentido da burocratização do Estado brasileiro, que buscava introduzir em seu aparelho administrativo a centralização, a impessoalidade, a hierarquia, o sistema de mérito e a separação entre o público e o privado (COSTA, 2Oo8b).

Martins (I997a), contudo, argumenta que o Brasil nunca chegou a ter um modelo de burocracia pública consolidado. O que se constatou é a presença de um padrão híbrido de burocracia patrimonial. Schwartzman (I998), por exemplo, afirma que a continuidade do modelo de Administração Pública patrimonial é uma das marcas do nosso Estado. 
Convém destacar que tal hibridização não foi exclusividade na esfera federal. Codato (I997), ao discutir a criação dos DAE’s - Departamentos Administrativos dos estados (também chamados de "Daspinhos") chama a atenção para o fenômeno. Para o autor (I997, p.II5), "esses aparelhos constituíram uma solução bastante original para o problema da representação de interesses no regime ditatorial”. Analisando o DAE em SP, o autor destaca seu caráter híbrido, ao ser criado com o propósito de, ao mesmo tempo, articular e agregar interesses, acomodando a complexidade das situações políticas regionais, divididas e em grupos submetidas exclusivamente ao reduzido jogo político dos Interventores.

Para Costa (2008a), o Dasp representou a concretização desses princípios burocráticos, uma vez que se tornou a grande agência de modernização administrativa, encarregada de implementar mudanças, elaborar orçamentos, recrutar e selecionar servidores, treinar o pessoal, racionalizar e normatizar as aquisições e contratos e a gestão do estoque de material. Segundo o autor, o Dasp foi relativamente bem-sucedido até o início da redemocratização em 1945, quando houve uma série de nomeações sem concurso público para vários organismos públicos. "A liberdade concedida às empresas públicas, cujas normas de admissão regulamentadas pelos seus próprios estatutos tornavam facultativa a realização de concursos foi em parte responsável por tais acontecimentos" (COSTA, 20o8a, p.I57).

Segundo Wahrlich (1984), tais atitudes revelavam que o favoritismo tinha maior peso que as admissões por mérito no sistema brasileiro de administração de pessoal dos órgãos públicos. Contribuíram para isso, "o ambiente cultural encontrado pela reforma modernizadora. (...), o mais adverso possível, corroído e dominado por práticas patrimonialistas amplamente arraigadas" (TORRES, 2004, p.I47).

Apesar do esforço do governo para conter os excessos da expansão da administração centralizada, o modelo burocrático de administrar começou a entrar em decadência a partir de I970, crise esta que apresentou várias dimensões (MATIASPEREIRA, 2008): da estratégia (foco e convergência de programas e ações), da estrutura (lenta, excessiva em alguns setores, escassa em outros), dos processos (sujeitos às regras padronizadas), dos recursos (inadequados, desde os logísticos e instalações à tecnologia), da cultura (excessivamente burocrática e permeável às práticas 
patrimonialistas) e das pessoas (com distorções relativas à distribuição, carência, qualificação e remuneração).

Ferreira (I999), de outra parte, acredita que a burocracia não pode ser considerada criadora de falhas na Administração Pública. Para o autor, ao contrário, esse modelo contribuiu na fase de estruturação dos governos, quando buscou racionalizar as ações governamentais. Marini (2003) considera que a adoção dos princípios do modelo burocrático pela Administração Pública foi fundamental para frear a lógica patrimonialista.

Bresser Pereira (1996), todavia, ressalta os limites do modelo burocrático. Para o autor, esse modelo demonstrou-se ineficiente quando o Estado assumiu um número crescente de serviços sociais e econômicos. Neste sentido, em resposta a tais limitações, à expansão das funções econômicas e sociais, ao desenvolvimento tecnológico e à globalização, emerge a administração pública gerencial (BRESSER PEREIRA; SPINK, 2005).

\section{Administração Pública gerencial}

Desde o final da década de ı970, a reforma do Estado tornou-se tema central em quase todo o mundo, fazendo com que a introdução do modelo gerencial no setor público começasse a ganhar força (ABRÚCIO, I997). O autor aponta quatro fatores socioeconômicos que contribuíram fortemente para detonar a crise do Estado contemporâneo: o primeiro deles é a crise econômica mundial, iniciada em I973, com a primeira crise do petróleo e retomada ainda com mais força em I979. O segundo, a ordem fiscal que veio enfraquecer os alicerces do antigo modelo de Estado. Após ter crescido por décadas, a maioria dos governos não tinha mais como financiar seus déficits. O terceiro, aquilo que a linguagem da época chamava de "situação de ingovernabilidade"; e quarto, a globalização e todas as transformações tecnológicas, que transformaram a lógica do setor produtivo e afetaram profundamente o Estado.

No Brasil, a primeira tentativa de reforma gerencial ocorreu a partir do Decretolei $200^{3}$, no final da década de 1960 . Segundo Bresser Pereira (2005), por meio desse

${ }^{3}$ O Decreto-lei 200, de 25 de fevereiro de 1967, era uma espécie de lei orgânica da Administração Pública, fixando princípios, estabelecendo conceitos, balizando estruturas e determinando providências (COSTA, 2008b).

Revista Administração em Diálogo

ISSN 2178-0080

Programa de Estudos Pós-Graduados em Administração

Pontifícia Universidade Católica de São Paulo 
decreto-lei, estabeleceram-se algumas diretrizes para a reforma administrativa: planejamento e orçamento; expansão das empresas estatais (sociedades de economia mista e empresas públicas) e dos órgãos independentes (fundações públicas) e semiindependentes (autarquias); necessidade de fortalecimento e expansão do sistema do mérito, sobre o qual se estabeleciam diversas regras; diretrizes gerais para um novo plano de classificação de cargos; reagrupamento de departamentos, divisões e serviços em I6 ministérios. Ainda segundo o autor, a reforma iniciada com o Decreto-lei 200 foi uma tentativa de superar a rigidez burocrática, sendo considerada como primeiro momento da administração gerencial no Brasil.

Identifica-se, contudo, como principal marco de reforma gerencial no país a ação empreendida pelo Ministério da Administração e Reforma do Estado (MARE), na pessoa de Luis Bresser Pereira, durante o primeiro governo de Fernando H. Cardoso (BRESSER PEREIRA, I997). Tal modelo fundamentava-se em experiência internacional, uma vez que outros países já o haviam adotado, como a Grã-Bretanha, em I979 (governo Thatcher), e os Estados Unidos, em I980 (governo Reagan), onde o enfoque gerencial da administração pública manifestou-se primeiro. Em ambos os países, principalmente na Grã-Bretanha, o serviço público tradicional passou por profunda transformação, perdendo os traços burocráticos e adquirindo características gerenciais (ABRÚCIO, 2005).

Bresser Pereira (I999) identifica três objetivos para a reforma do Estado de I995: aumentar a eficiência e a efetividade dos órgãos do Estado, melhorar a qualidade das decisões estratégicas do governo, e assegurar o caráter democrático da Administração Pública. Para o autor, as características da nova gestão seriam: descentralização e desconcentração das políticas e atividades públicas, separação dos órgãos formuladores e executores, controle gerencial das agências autônomas, distinção de dois tipos de unidades descentralizadas (agências que realizam atividades exclusivas de Estado e serviços sociais em que este poder não está envolvido), transferência para o setor público não estatal dos serviços sociais e terceirização das atividades auxiliares.

Para atingir os objetivos, ao elaborar o PDRAE 1995, Bresser Pereira e equipe propuseram duas emendas constitucionais para legitimar a reforma administrativa. A primeira propunha alterações relativas aos recursos humanos, tendo como premissa 
corrigir "alguns equívocos da constituição de I988, como a institucionalização do regime jurídico único dos servidores públicos” (PDRAE, 1995, p. 27).

A segunda emenda se referia à "autonomia dos três poderes e a fixação de vencimentos dos servidores da administração pública, excluídos os titulares de poder” (PDRAE, I995, p. 52). As alterações propostas nas emendas causaram reações como greve e manifestações por parte dos servidores e sindicatos.

Ressalte-se ainda o caráter neoliberal da reforma de Estado da década de 1990, dada a forte influência das reformas britânica e americana, na brasileira. O modelo neoliberal, além de fazer ruir o movimento sindical, gerou um alto índice de desemprego e um amplo programa de privatização das empresas públicas. Apesar das consequências, o governo brasileiro seguiu as regras do consenso de Washington ao implantar a reforma de I995.

Abranches (1999) já afirmava, àquela época, que o governo brasileiro não tinha ainda "um saber" sobre a reforma do Estado. O que prevalecia era a ideia de redefinição do Estado brasileiro, que deixa de ser burocrático e intervencionista para se tornar regulador (ABRANCHES, I999; COSTA, 2008a). Para Abranches (I999), o PDRAE estabeleceu uma doutrina setorial, sem uma concepção explícita sobre a natureza operacional do novo Estado. Abrúcio (1997) ressalta que a reforma enfrentou um problema estrutural, uma vez que boa parte do sistema público tem um cálculo de carreira que bate de frente com a modernização administrativa. Profissionalizar a burocracia e avaliá-la contrasta com o fisiologismo dos políticos. Os cargos e verbas públicos até hoje são usados como forma de barganha. "Baseia-se em valores e práticas tradicionais: assenta grande parte do poder político no distanciamento autoritário, no paternalismo e no exercício da bondade" (MOTTA, 2007, p. 9I).

Diniz (I998) explica que o desenho institucional trazido pela nova Administração Pública aumentou o isolamento dos decisores, estimulando as práticas personalistas e voluntárias. Paula (2005), por sua vez, ressalta que a política de recursos humanos proposta pela reforma do Estado mantém a diferenciação entre os escalões governamentais, pois tenta fortalecer a alta burocracia por meio do projeto de contratação e formação de especialistas e procura isentar o Estado do recrutamento, formação e qualificação dos escalões inferiores, que seriam idealmente transferidos para 
a responsabilidade do setor privado.

Percebe-se, assim, que o Estado e a Administração Pública no Brasil foram e são marcados pelo hibridismo. Apesar das reformas, há permanência do patrimonialismo na administração. Tal fato pode-se perceber, ainda hoje, na prática política do país a transferência de poder semelhante à dominação doméstica, principalmente nos estados. À medida que vai ficando mais velho, o pai já articula para eleger como sucessor "o filho ou a filha”, que continuará a ser o “coronel” da região.

Um dos desafios da reforma no Brasil é lidar com os paradoxos decorrentes desse hibridismo administrativo e do decorrente formalismo.

\section{Formalismo e a Construção do Brasil}

Segundo Riggs (I96I), o formalismo é a discrepância entre a conduta concreta e a norma prescrita que se supõe regulá-la. Registra-se ali onde o comportamento efetivo das pessoas não observa as normas estabelecidas que lhe corresponda, sem que disso advenham sanções para os infratores.

A fim de caracterizar os diferentes modelos de sociedade, Riggs (I968) utiliza o critério do formalismo, embora recorra também a dois outros: o de heterogeneidade e o de superposição. Superposição, segundo Riggs (I968), é o exercício cumulativo de funções diferentes por uma mesma unidade social, em que funções administrativas, políticas, econômicas e educacionais são exercidas por uma mesma agência. A heterogeneidade se exprime materialmente, sob a forma de mistura de elementos tecnológicos, modernos e antigos, urbanos e rurais. Também nas condutas humanas se registram idênticas disparidades: costumes, hábitos, atitudes e estilos de alta sofisticação. Riggs (I968) propõe três tipos ideais de sociedade: concentradas - países extremamente subdesenvolvidos; difratadas - países desenvolvidos; prismáticas - países em desenvolvimento.

Ao discutir o tema "Formalismo no Brasil", Guereiro Ramos (I966) aponta-o como uma estratégia de modernização institucional e de construção nacional. Isso, devido ao que viveu a primeira geração de políticos do "Brasil-Nação", logo após a independência do país. Após a Independência, em I822, os políticos se viram no dever de criar as instituições e leis que servissem de suporte para governar o País. Estando em 
uma situação menos evoluída politicamente do que as sociedades difratadas, os políticos optaram por se espelharem nas leis das velhas nações: Inglaterra, Estados Unidos e França.

De acordo com Guerreiro Ramos (ig66), Paulino José Soares de Souza, o Visconde do Uruguai, destacou-se entre os que se preocuparam com os problemas administrativos do Brasil. Ele condenou a transplantação literal e mecânica de instituições políticas e administrativas das velhas nações para o Brasil. Para ele, a criação das instituições no Brasil deveria ter em vista as condições efetivas e as particularidades histórico-sociais do meio nacional. Foi ainda grande defensor da centralização política e administrativa contra aqueles que, influenciados por ideias em voga no exterior, principalmente na Inglaterra, esmeravam-se na defesa da autonomia das províncias e municípios. Guerreiro Ramos (I966) defendia que a construção do país não deveria tornar-se uma simples transplantação das leis das nações mais velhas à sociedade subdesenvolvida. Era necessário que correspondesse ao contexto e à cultura do Brasil.

Guerreiro Ramos (1966; I983) salienta que os três poderes nas nações mais velhas foram, primeiramente, uma realidade, costumes consagrados, e, depois, uma teoria formal. No Brasil, devido à sua formação histórica, a formação foi inversa:

Não caminhamos do costume para a teoria; do vivido, concreta e materialmente, para o esquema formal. É o inverso que se dá; caminhamos até agora, no tocante à construção nacional, do teórico para o consuetudinário, do formal para o concretamente vivido (GUERREIRO RAMOS ı966, p. 388).

Entendia-se que, em plena construção nacional, os políticos, que até então eram tidos como membros de uma sociedade prismática, que se caracterizava pela "rusticidade tropical”, não podiam compor as instituições do país com poderes que não fossem reconhecidos. Diversamente, esses poderes tiveram que ser aqui implantados e organizados segundo as prescrições da cultura jurídica universal (GUERREIRO RAMOS; г966).

Riggs (I968) acredita que o formalismo, em particular, remete a sociedade a circunstâncias em que os valores eleitos são distintos dos valores verdadeiros, tradicionais da sociedade. Para Machado-da-Silva et al. (2003), em uma sociedade como a brasileira, fortemente influenciada por padrões ou modelos estrangeiros, torna-se mais fácil adotar uma estrutura formal por decreto ou lei do que institucionalizar o 
correspondente comportamento social.

Ainda de acordo com Guerreiro Ramos (เ966; г983), o formalismo na sociedade brasileira, como em toda sociedade prismática, revela-se, essencialmente, como estratégia quando examinado do ponto de vista do mundo; uma fase paradigmática que toda sociedade prismática vivencia como estratégia de "superação do caráter dual da sociedade” (GUERREIRO RAMOS, I966, p. 42I). Para ele, a dualidade da economia e da sociedade no Brasil não é acidental; é exigência objetiva do modo histórico pelo qual o país se articulará com o mundo enquanto, internamente, não existir um conteúdo econômico-social equivalente ao dominante no exterior.

Sobre a questão do formalismo na construção nacional do país, Faoro (2000) coloca a questão de o conteúdo das leis contradizer os costumes, a tradição e as necessidades da população: “a vida social será antecipada pelas reformas legislativas, esteticamente sedutoras, assim como a atividade econômica será criada a partir do esquema, do papel para a realidade" (FAORO, 2000, p. 376).

O formalismo continua sendo uma característica dominante em todo o processo de formação da nação brasileira, que marca o caráter nacional. Ainda hoje, as leis e os modelos de gestão continuam sendo "transcritos" de outros países, implantados nas organizações e impostos à sociedade brasileira sem uma rigorosa crítica e adequação cultural. Não se pretende ficar como opositores do uso de modelos de gestão pública ou privada que deram certo em determinada nação para a realidade cultural do Brasil. Há de se ressaltar, contudo, que as organizações públicas e os gestores não são como esponjas, que absorvem tudo, mas atores que respondem à mudança, guiados por instituições existentes (SCHOMMER, 2OO3).

Atualmente, as contratações e os recrutamentos amplos no serviço público ilustram a discrepância entre a conduta concreta e a norma prescrita que se supõe regulála. O abuso dos governantes dos poderes Executivo, Legislativo e Judiciário levou o Supremo Tribunal Federal a aprovar a Súmula Vinculante I3 (2008), que veta a contratação de parentes em até terceiro grau, incluindo cônjuges, para cargos da Administração Pública direta e indireta da União, dos estados, do Distrito Federal e dos municípios. Vetou também as chamadas "contratações cruzadas". O fato vem reforçar a necessidade do instrumento burocrático para combater o uso do patrimonialismo na 
Administração Pública.

Riggs (196I) interpreta que a existência do formalismo faz com que as instituições e as pessoas possam dar, negar, vetar e consentir determinado comportamento. $\mathrm{O}$ fato de ocorrer o desrespeito a algumas leis em determinada sociedade faz com que haja uma generalização da desconfiança em torno da validade de todas as suas demais leis. Nesse contexto, Guerreiro Ramos ( 1966 ; 1983$)$ define o "jeito" como o genuíno processo brasileiro de resolver dificuldades, a despeito do conteúdo das normas, códigos e leis. É o formalismo que acarreta a prática do “jeito", sendo o formalismo uma estratégia primária e o jeito uma estratégia de segundo grau, suscitada pelo formalismo. Hirschman (I965) chama o formalismo de "tratamento remediador" de problemas, o qual seria: realista, flexível, pragmático e mudança adaptativa.

Diante desse contexto, é interessante observar e analisar de que modo esse caráter formalista ainda existente na Administração Pública interfere na execução e na prática da reforma do Estado.

\section{Procedimentos Metodológicos}

O método de pesquisa utilizado neste trabalho foi o estudo de caso, de caráter qualitativo. A unidade de análise desta pesquisa foram os setores e os servidores do Órgão do Poder Judiciário Federal pesquisado. A unidade de observação foi composta por: base legal produzida pelo Poder Executivo, Tribunal Superior e Tribunal Regional relativa à reforma do Estado; servidores do Tribunal, analistas e técnicos judiciários.

Os sujeitos da pesquisa correspondem aos servidores da Secretaria de Gestão de Pessoas, selecionada por ser responsável pela gerência de recursos humanos do tribunal. Os sujeitos foram selecionados com base nos critérios de tipicidade e acessibilidade. Tendo como base o tempo de serviço na instituição e a acessibilidade, foram escolhidos para serem entrevistados I2 servidores, "levando em consideração o fechamento amostral por saturação teórica" (FONTANELLA, RICAS e TURATO, 2008). A amostra final foi composta por quatro ingressantes no Tribunal antes da reforma de r995 e quatro, após 1995. Além desses, foram selecionados para entrevista quatro gestores.

A coleta de dados amparou-se na análise dos documentos legais produzidos pelo poder executivo e Tribunais. Os dados primários foram coletados, por meio de 
observação participante (FLICK, 2009), nas seções da Secretaria de Gestão de Pessoas do Tribunal e de entrevistas semiestruturadas, realizadas com quatro gestores e oito servidores. Foram feitos dois roteiros de entrevista, um para os gestores e outro para os servidores. O objetivo foi, por meio de questões relativas à reforma do Estado de $1995 \mathrm{e}$ as alterações ocorridas na lei 8.I12/9o, conhecer a opinião dos servidores sobre a influência do formalismo na prática da reforma, além de analisar traços patrimonialistas e burocráticos na implantação da reforma. Optou-se pela análise temática do conteúdo, uma vez que é transversal e permitiu um recorte dos dados primários coletados, para que deles fossem extraídos os fatos relevantes à pesquisa.

\section{Apresentação e Análise dos Resultados}

Os gestores entrevistados foram nomeados como Eı a E4, sendo EGA gestor que ingressou antes de I995 e EGN aquele que ingressou após 1995. Os servidores foram identificados como E5 a Eı2; os servidores novos, aqueles que ingressaram após I995 foram caracterizados como ESN e os antigos, os que entraram antes de r995 como ESA.

De maneira geral, percebeu-se, no Tribunal, o hibridismo dos três modelos de administração pública. Na observação pode-se constatar a existência de características dos três modelos. Tal realidade reforça o entendimento de Abrúcio (i997), de que "o quadro administrativo brasileiro é marcado por uma multiplicidade de situações, um modelo híbrido muito peculiar”. Uma das características do patrimonialismo observada foi a indicação de pessoas fora do quadro de servidores do Tribunal para ocuparem certos cargos de chefia e assessoramento. Em geral, os indicados para os cargos em comissão são amigos ou afilhados. Essa prerrogativa de cargos é prevista na lei II.4I6/2006 a qual proporciona ao presidente dos Tribunais a possibilidade de nomear à sua escolha, em percentuais específicos, para cargos e funções comissionadas, pessoas que não fazem partem do quadro de servidores.

Apesar da presença de elementos do patrimonialismo, foi possível identificar algumas características do modelo burocrático nas seções observadas: os comunicados são formais, o trabalho é dividido, há presença da hierarquia do trabalho e de autoridades, mantém-se caráter legal das normas e regulamentos e, apesar da informatização, prevalece o uso do processo físico em papel e o controle dos 
procedimentos. Um exemplo do controle dos procedimentos é a avaliação de desempenho, do servidor em estágio probatório, realizada em atendimento à resolução 22.582 de 2007. Ainda que o Tribunal seja dotado de um sistema informatizado, por meio do qual são feitos a avaliação do servidor e o cálculo da nota obtida por ele, classificando-o como aprovado ou não, todo esse processo é controlado pelo processo físico, em papel, com a assinatura de todos os interessados.

Foram também identificadas, na observação realizada, características da administração gerencial como: terceirização dos serviços, flexibilização do horário, sistemas informatizados, transparência, incentivo a criatividade e inovação, profissionalização, capacitação do servidor e administração voltada para o atendimento do cidadão. Destacam-se ainda algumas ações tais como a criação da ouvidoria em março de 2009, o concurso de monografia e o cursos de capacitação profissional presencial e à distância para os servidores.

Percebeu-se também que a prática do formalismo é institucionalizada pelo órgão na medida em que, por meio de instrução normativa, oficializou-se a jornada de trabalho e a compensação de horário. Para legalizar o hábito, a administração do tribunal concedeu-lhe um caráter normativo, definindo, assim, o seu modo de agir. Para Machado-da-Silva et al (2003), um dos traços indicadores da presença do formalismo é a "transformação em regras ou normas das decisões sobre o funcionamento da instituição e o comportamento dos funcionários”.

Acerca da opinião dos gestores sobre a reforma do Estado de 1995, houve a prevalência de conteúdo negativo nas respostas, conforme demonstra a Tabela I. ${ }^{4}$

Tabela I - Opinião dos gestores sobre a reforma do Estado de $1995(\mathrm{n}=4)$

\begin{tabular}{l|c} 
Respostas & F \\
\hline Houve perda dos direitos adquiridos pelo servidor. & 3 \\
\hline A reforma só trouxe prejuízos para o servidor. & 2 \\
\hline Foi uma reforma visando o Estado e não o servidor. & 1 \\
\hline Para o estado sim, a reforma foi um grande ganho. & 2 \\
\hline Houve corte de benefícios. & 2 \\
\hline Visou enxugar a máquina estatal. & 1 \\
\hline O servidor público foi tratado como sendo o grande vilão. & 1 \\
\hline A reforma foi aprovada em detrimento do servidor de carreira. & 2
\end{tabular}

Fonte: Dados coletados da pesquisa

${ }^{4}$ As tabelas indicam as respostas dos entrevistados, e frequência em que aparecem nas falas analisadas. 
Eis a opinião dos entrevistados, E3 e E4 sobre a reforma do Estado de I995: "Foi prejudicial para o servidor. O discurso é que a reforma iria diminuir custos e racionalizar, mas isto nunca foi provado. Só trouxe prejuízos para o servidor (EGA3, 2009)”. "A meu ver, objetiva enxugar a máquina estatal, sem se preocupar com os direitos já adquiridos pelos servidores públicos, decorrentes de décadas de luta (EGA4, 2009)”.

Quanto ao posicionamento sobre a reforma, os dados demonstram que o gestor que ingressou após 1995, além de comentar a respeito das perdas para o servidor, reconhece que "para o Estado sim a reforma foi um grande ganho". Por sua vez, os gestores que estavam no serviço público desde a década de 1980 se posicionaram mais em defesa dos direitos perdidos com a reforma do Estado:

Tirou direitos adquiridos pelo servidor ao longo de muitos anos. Foi uma reforma visando o Estado e não o servidor (EGAı, 2009).

O servidor público foi tratado como sendo o grande vilão e o culpado pelos desajustes e descontrole do orçamento público. Em nome do princípio da eficiência, a reforma foi aprovada, em detrimento do servidor de carreira (EGA4, 2009).

Com relação à implantação das alterações ocorridas na lei 8Iı2/9o em I996 e I997 no Tribunal, os gestores foram unânimes na colocação de que todas as alterações advindas com a reforma foram aplicadas pelo órgão imediatamente.

As informações dos entrevistados vêm reforçar os resultados obtidos na observação, ou seja, a presença dos modelos burocrático e gerencial na administração do Tribunal. Isso vem demonstrar que um modelo não exclui o outro, pelo contrário, a administração pública gerencial está apoiada na burocrática (PDRAE ${ }^{5}$, I995). Esta é também a opinião de Abrúcio (I997) ao analisar o modelo gerencial de diversos países. Para o autor, o modelo gerencial é um pluralismo organizacional sob a proteção das bases pós-burocráticas (ABRÚCIO, 1997).

Em relação à avaliação de desempenho aplicada aos servidores, na opinião dos gestores, apesar de ter havido progresso em alguns itens, ela ainda não é utilizada pela administração conforme estabelece a resolução $22.5^{82}$ de 2007:

5 Plano Diretor da Reforma do Aparelho do Estado.

Revista Administração em Diálogo

ISSN 2178-0080

Programa de Estudos Pós-Graduados em Administração

Pontifícia Universidade Católica de São Paulo 
Art. $6^{\circ}$ são finalidades da Avaliação de Desempenho:

I - verificar a aptidão do servidor para o exercício das atribuições do cargo efetivo, no período do estágio probratório;

II - subsidiar a concessão de progressão funcional e promoção;

II - detectar necessidades de capacitação e desenvolvimento;

IV-identificar necessidades de adequação na lotação do servidor (Resolução $22.5^{82}$ de 3 o de agosto de 20Oz).

Como demonstra a Tabela 2, a avaliação de desempenho aplicada no órgão ainda é comportamental, não atende às finalidades para as quais foi criada.

Tabela 2 - Opinião dos gestores sobre a avaliação de desempenho $(n=4)$

\begin{tabular}{l|c} 
Respostas & $\mathrm{F}$ \\
\hline A avaliação feita antes da reforma era um horror. & 4 \\
\hline A avaliação ainda é comportamental. & 1 \\
\hline $\begin{array}{l}\text { Pretende-se utilizá-la como recurso para montar os treinamentos e } \\
\text { qualificação. }\end{array}$ & 1 \\
\hline $\begin{array}{l}\text { O ideal é que houvesse a participação direta do próprio servidor através da } \\
\text { auto avaliação. }\end{array}$ & 2 \\
\hline $\begin{array}{l}\text { Antes da reforma a administração tinha que ter metade dos servidores ruins } \\
\text { ou em um nível abaixo. }\end{array}$ & 1 \\
\hline \begin{tabular}{l} 
Precisa ser melhorada, em vários aspectos. \\
\hline
\end{tabular}
\end{tabular}

Fonte: Dados coletados da pesquisa

Percebe-se uma discrepância entre a resolução e a sua aplicação prática. Há o predomínio da heterogeneidade nas relações, o confronto do comportamento antigo pessoal, com a profissionalização e a impessoalidade defendidas pela burocracia gerencial. Essa discrepância reforça a opinião de Machado-da-Silva et al (2003), o formalismo é uma instituição presente na sociedade brasileira.

As características do formalismo foram auferidas por meio da "sociologia do jeito" (GUERREIRO RAMOS, I966) com relação à concessão do Adicional de Qualificação $^{6}(\mathrm{AQ})$ regulamentado no Tribunal pela resolução 22.576, em 28 de agosto de 2007. Como a lei não restringe os cursos que devem ser aceitos, fica a cargo do administrador avaliar e decidir quais cursos, além do de Direito, serão aceitos para o Adicional de Qualificação, preservando, assim, o caráter discricionário da administração pública. Ou seja, como a decisão depende do administrador, antes de fazer o curso o

${ }^{6}$ Adicional de Qualificação - AQ destinado aos servidores das Carreiras dos Quadros de Pessoal do Poder Judiciário, em razão dos conhecimentos adicionais adquiridos em ações de treinamento, títulos, diplomas ou certificados de cursos de pós-graduação, em sentido amplo ou estrito, em áreas de interesse dos órgãos do Poder Judiciário (art. 14 da Lei 11.416 de 15 de dezembro de 2006).

Revista Administração em Diálogo

ISSN 2178-0080

Programa de Estudos Pós-Graduados em Administração

Pontifícia Universidade Católica de São Paulo 
servidor consulta o setor responsável pela concessão do AQ para saber se o curso é aceito ou não. Caso seja, ele faz a sua matrícula e realiza o curso. E quando o curso que ele pretende realizar não é aceito pelo Tribunal, ele realiza um dos que são aceitos. $\mathrm{Na}$ observação, verificaram-se casos em que o curso não era aceito, mas, após análise da grade curricular decidiu-se pela concessão. Segundo Guerreiro Ramos (I966), o formalismo é uma modalidade estratégica que acarreta a prática do "jeitinho” brasileiro de resolver dificuldades de entendimento ou prática com relação às leis e normas.

A análise das respostas dos entrevistados quando solicitados a opinar sobre o critério utilizado para indicar as pessoas que ocupam cargos em comissão, reforça que se percebeu durante a observação: existência de características patrimonialistas na administração, apesar das reformas administrativas por que o país passou.

[...] Mas ela acaba sendo subjetiva, porque a própria lei cria critérios; então a gente pode questionar a lei mas não o administrador que está avaliando. Se para ele aquela pessoa que ele está nomeando é competente, pode até ser que não seja para nós mas não há um critério objetivo. Agora, o que a gente vê é administrações que abusam dessa regra e outras que não. No Tribunal, por exemplo, nós temos limites para o recrutamento amplo (EGAI, 2009).

Observe-se a opinião dos servidores entrevistados sobre a reforma do Estado é de que houve poucas alterações na administração. Em relação aos oito entrevistados, a frequência de respostas para os prejuízos foi de 3 , frequência igual às respostas que consideram um ponto positivo para a administração pública. Uma frequência de respostas considera que a reforma ficou mais no papel do que na prática, conforme resultados da Tabela 3 .

Tabela 3 - Opinião dos servidores sobre a reforma do Estado de 1995 ( $\mathrm{n}=8$ )

\begin{tabular}{l|c}
\multicolumn{1}{c|}{ Respostas } & F \\
\hline A reforma foi um prejuízo para os servidores. & 3 \\
\hline Antes da reforma não havia um critério rígido para os servidores subir de nível. & 1 \\
\hline $\begin{array}{l}\text { A reforma ela foi um pontapé para a evolução do serviço público. Foi direcionada para o } \\
\text { cliente, para a sociedade. }\end{array}$ & 4 \\
\hline A reforma foi positiva para o estado brasileiro. & 3 \\
\hline $\begin{array}{l}\text { Na verdade eu não tenho opinião formada porque como eu entrei para o serviço público } \\
\text { só recentemente. }\end{array}$ & 1 \\
\hline $\begin{array}{l}\text { A reforma só trouxe benefícios no papel; na prática a teoria é outra. } \\
\text { Na prática, as alterações da reforma foram implantadas somente em torno de 40\%. Ainda } \\
\text { tem muito a melhorar. }\end{array}$ & 4
\end{tabular}

Fonte: Dados coletados da pesquisa 
Verificou-se pela análise das entrevistas que na opinião dos servidores novos, dois consideraram que a reforma foi positiva para o serviço público, um não opinou e um considerou que trouxe prejuízo. Esclarece-se que o servidor que considera prejudicial era servidor em outro órgão público antes da implantação da reforma do Estado. Dos quatro servidores antigos, três a consideram positiva e outro acredita que seus benefícios ficaram apenas no papel. De acordo com as respostas dos servidores:

Olha, para mim foi uma reforma muito intensa, muito complexa. Ela trouxe consequências para todos os âmbitos, todos os âmbitos administrativos do Estado e do Judiciário, porque teve que haver uma adequação das exigências que estavam lá fora. Muitos princípios adotados na iniciativa privada tiveram que ser incorporados à iniciativa pública para adequar [...] eu acho que a reforma foi um pontapé para a evolução do serviço público direcionado para o cliente, para a sociedade (ESN7, 2009).

Apesar de ela ter atingido em cheio o servidor público eu concordo com mudança, mas no sentido amplo, porque ela ficou sem efeito porque, apesar de ser uma servidora pública e de estar satisfeita com os benefícios que eu tenho hoje, os benefícios que eu teria hoje caso a mudança não ocorresse seriam muito maiores. Mas a gente não pode pensar egoisticamente só em nós servidores públicos, nós temos que pensar no país. O Brasil é um país pobre, então é um privilégio absurdo! Você para de trabalhar e aí você continua carregando tudo aquilo que você ganhava enquanto você estava na ativa. Você estava produzindo, é claro que você trabalhou 20, 25, 30 anos, você merece! Não só o servidor público, mas qualquer cidadão brasileiro merece! (ESA8, 2009).

Observa-se nas informações obtidas a presença do formalismo na aplicação da reforma do Estado "na prática a teoria é outra, a minha percepção é assim é que ficou muito bonito no papel” (ESAıı, 2009). Na opinião de ESAıI, na prática as alterações foram muito pequenas, houve mais barulho do que ação.

Ao analisar a fala de ESAı2, percebem-se alguns reflexos da disfunção burocrática na implantação da reforma: "[...] gestores com uma visão retrógrada, [...] boa parte dos gestores não tinham noção do que estava acontecendo e pior que isso era contra a questão moderna" (ESAı2, 2009).

Observa-se na fala de ESAıı a presença do formalismo com relação à progressão do servidor na carreira "quando eu entrei aqui é que assim eu comecei em um nível, um nível como é que chama aquele nível [...]: Aı e rapidinho dentro de três meses eu cheguei ao final de carreira”. Enquanto a lei diz que o servidor deve percorrer I5 níveis, ou seja, I5 anos de exercício para atingir o final de carreira na prática o servidor atingia o final de carreira em três meses. Ressalta-se que com a reforma e os planos de carreira do 
judiciário esta situação foi alterada. Atualmente a progressão funcional ocorre de acordo com a lei.

Quanto à avaliação de desempenho, na opinião dos servidores entrevistados, ela ainda é falha, e sua aplicação e as notas são discrionárias. Para três dos servidores novos, a avaliação é utilizada como um instrumento burocrático de controle e autoridade, "Não visa o desenvolvimento do servidor" . Na opinião dos servidores antigos, três descrevem a avaliação como formalística e paternalista, e um considera a avaliação burocrática e paternalista. Veja-se na Tabela 4 a frequência das respostas.

Tabela 4 - Opinião dos servidores sobre a avaliação de desempenho $(\mathrm{n}=\mathbf{8})$

\begin{tabular}{l|l}
\multicolumn{1}{c|}{ Respostas } & F \\
\hline A avaliação poderia ser mais profunda, melhor explorada pelos gestores. & 3 \\
\hline Ao responder a avaliação há certa pressão. & 2 \\
\hline $\begin{array}{l}\text { Antes da reforma o chefe fazia a avaliação e servidor não tinha } \\
\text { conhecimento. }\end{array}$ & 2 \\
\hline A avaliação existia somente no papel. & 2 \\
\hline Os chefes avaliam pela empatia que têm com o funcionário. & 2 \\
\hline A avaliação de desempenho é válida & 2 \\
\hline A avaliação não é utilizada como instrumento de gestão. & 2
\end{tabular}

Fonte: Dados coletados da pesquisa

Ao analisar a fala de ESA8, chama a atenção sua opinião sobre a aplicação da avaliação de desempenho no Tribunal. Sua fala demonstra o uso de valores e práticas tradicionais na administração pública, conforme destaca Motta (2007): “[...] alguns casos de chefes que não estão preparados para lidar com funcionário. Eles avaliam a pessoa não pelo desempenho, mas eles avaliam pela empatia que eles têm com o funcionário (ESA8, 2009)".

Destacam-se na fala de ESA9 e ESAı2 características do patrimonialismo e do formalismo na aplicação da avaliação de desempenho quando eles explicam que, na prática, a avaliação não era aplicada ao servidor, ela existia na lei. $\mathrm{O}$ chefe avaliava o servidor sem que este soubesse. A avaliação era utilizada pelo chefe como instrumento de poder. Esse relato confirma a teoria de autores como (FREYRE, I973; FAORO, 2OoO; WEBER, 2004; HOLANDA, 2006) da predominância do personalismo, da vontade particular e da cordialidade na administração patrimonialista. 
[...] ela era só no papel, inclusive pelas histórias que eu escuto aqui no Tribunal... As promoções eram feitas em cima dessas avaliações. Eles faziam um alternado escolhiam alguém para ser promovido e davam aquela avaliação melhorada [...] porque antes tinha até as promoções que não eram de... Como é que se diz, era aquela antes de 88? Era ascensão! [...] mas, se eu não estou enganado, eu lembro que isso era até usado nessa troca. Então isso era péssimo... E não se usava nenhum critério lógico para fazer isso; era aquela questão assim: que eu gostei de você, ao fazer o rodízio e vou te colocar primeiro (ESA9, 2009).

[...] a idéia é excelente, mas eu acho que a forma como ela é colocada é muito delicada e, se por um lado ela pode te motivar, por outro pode ser um grande frustrador para o servidor, dependendo da forma como ela é colocada. Eu até vou mencionar, eu não tenho restrição em mencionar isso, que a primeira avaliação à qual eu fui submetida eu não fui comunicada, eu não sabia que teria essa avaliação (ESAı2, 2009).

A respeito do Adicional de Qualificação concedido ao servidor com o plano de carreira do judiciário, tanto na opinião dos servidores novos como dos antigos foi uma alteração importante, pois incentiva o servidor a buscar uma profissionalização. Grande parte dos servidores novos destaca nas respostas a importância de a instituição fazer um trabalho de conscientização, mostrando aos servidores a importância da aplicação do conhecimento adquirido com o curso no Tribunal. Esse fato é demonstrado na fala de ESN7: "eu acho que não está havendo um trabalho, uma movimentação, uma conscientização e para que as pessoas saibam que essa especialização tem que ter um retorno para a instituição, amanhã, de alguma maneira”.

Observa-se, na fala de alguns servidores sobre a concessão do horário especial e flexível, a presença do padrão híbrido de burocracia patrimonial na administração do Tribunal. Apesar de utilizarem o instrumento burocrático legal - o formulário - alguns gestores utilizam a "boa vizinhança" para autorizar ou não o horário. Situação que, conforme Junquilho (2003), demonstra a existência de traços patrimoniais na administração pública.

Olha o critério, como acho que quase tudo aqui dentro do Tribunal, é muito discricionário. A gente fica muito na mão do chefe imediato. Se ele concede, você acaba conseguindo. [...] às vezes, mesmo sendo uma necessidade sua, você nunca pode ter aquele horário, porque como falei, é discricionário, e o chefe pode não aceitar (ESN 7,2009$)$.

É totalmente formal, você pede ao chefe da seção, que passa para a coordenadora, que passa para a secretária [...] a secretária é que aprova (ESAII, 2009).

São perceptíveis, na fala dos entrevistados novos e antigos, traços da cultura brasileira desde a colonização, a saber, a pessoalidade, a cordialidade (FREYRE, I973; 
FAORO, 2O00; VASCONCELOS, 2002) e a mentalidade da casa-grande (HOLANDA, 2006). Esses traços presentes na indicação dos chefes e no tempo de permanência no cargo vêm reforçar a existência do patrimonialismo na administração do Tribunal:

É não há [...] o que eu vejo é que não há uma estabilidade. Veja bem, eu vivi um período no tribunal que a função era da pessoa era difícil você ver alguém perdendo uma função. [...]. Era um cargo vitalício, você tinha função você exercia até o momento que você abria mão (ESA9, 2009).

A presença do patrimonialismo na administração reforça a existência do formalismo, uma vez que a estrutura da organização não condiz com a lei. A administração gerencial prega que pelo menos $50 \%$ dos cargos em comissão deve se ocupados por servidores do quadro. Não justifica o Estado investir na profissionalização e no aperfeiçoamento do servidor, se ao indicar os gerentes não se levar em consideração a competência e o merecimento.

\section{Considerações Finais}

O modelo de administração adotado na gestão pública brasileira é híbrido, conforme entendimento predominante na literatura tratada nesta pesquisa. Esse hibridismo se dá pela combinação de traços paternalistas, corporativistas, burocráticos e até mesmo gerencial que prevalece nos gestores. Apesar desse caráter híbrido de administrar, três reformas de Estado foram propostas e implantadas pelos governantes do país na busca de modernizar a administração pública, tornando-a mais flexível e gerencial.

Tendo como base a reforma de Estado de 1995, esta pesquisa analisou como se dá a relação entre o formalismo e a execução da reforma do Estado em um Tribunal do Poder Judiciário Federal, na ótica dos servidores, tendo em vista a Lei 8.II2/9o e suas alterações.

A análise dos resultados permitiu afirmar que houve influência da administração patrimonialista, burocrática e gerencial na implementação da reforma, além da presença de traços formalísticos na administração.

$\mathrm{Na}$ visão dos gestores entrevistados, a reforma trouxe perda dos direitos adquiridos pelos servidores decorrentes de décadas de luta da categoria, causando corte dos benefícios e prejuízos aos que estavam no serviço público antes de I99o.

Ao contrário dos gestores, a maioria dos servidores considera a reforma como positiva para o Estado, por gerar uma melhor percepção da sociedade quanto ao servidor 
público.

A avaliação de desempenho instituída pelas alterações na lei 8п2/9o é considerada pelos servidores novos como mais um instrumento burocrático que, na verdade, não serve como um bom instrumento de avaliação. Os servidores antigos a consideram como um instrumento formalista e paternalista na mão dos gestores.

Durante a pesquisa percebeu-se que a maioria dos servidores aspira a um serviço público mais profissional, transparente e atuante na sociedade. Tal fato é comprovado, com a capacitação dos servidores, participação em trabalhos e workshop promovidos por outras instituições públicas e privadas.

Entretanto, o tribunal ainda não está preparado para absorver grande parte das inovações gerenciais, causando muitas vezes a desmotivação profissional. Tal fato foi demonstrado pelos servidores nas entrevistas, quando eles falam que a avaliação de desempenho não é utilizada como ferramenta de auxílio da gestão para programar os treinamentos necessários, na falta de critérios para indicar os chefes e na discricionariedade para conceder o AQ.

A pesquisa mostrou a presença do formalismo na implantação da reforma do Estado no Tribunal estudado, tanto na percepção dos gestores como dos servidores novos e antigos. Os resultados demonstram que quando não se considera a tradição da instituição, as leis e resoluções muitas vezes servem apenas como instrumento de normatização administrativa.

A discussão sobre as Reformas do Estado, em especial, a última de 1995, são comumente discutidas na arena acadêmica devido à sua importância conceitual para as ações do Estado. Este trabalho buscou expor o formalismo existente nesse processo, para que se possa discutir as barreiras e resistências para a implementação de um novo modelo de administração pública no país.

Convém, por fim, destacar que o presente estudo tem conclusões focadas num caso específico de um tribunal do poder judiciário. Sugere-se, assim, estudar outros Tribunais, com vistas a averiguar a aplicação e o desenvolvimento das alterações ocorridas na lei 8.m2/9o em relação ao desempenho funcional e profissional do servidor público, bem como analisar as consequências da aplicação do Adicional de Qualificação no aperfeiçoamento do servidor e do gestor público. 


\section{Referências}

ABRANCHES, Sérgio H. H. Reforma regulatória: conceitos, experiências e recomendações. Revista do Serviço Público - RSP. Brasília, ano. 5o, n. 2, p. 19-5o, abr./jun. I999.

ABRÚCIO, Fernando. O impacto do modelo gerencial na Administração Pública: Um breve estudo sobre a experiência internacional recente. Cadernos ENAP, Brasília, n. IO, I997

ABRÚCIO, F. Os Avanços e os Dilemas do Modelo Pós-Burocrático: A Reforma da Administração Pública à Luz da Experiência Internacional Recente. In: BRESSER PEREIRA, L. C.; SPINK, P. (Org.). Reforma do Estado e Administração Pública Gerencial. $6^{\text {a }}$ Ed. Rio De Janeiro: Fundação Getúlio Vargas, 2005.

BRASIL. Emenda constitucional ${ }^{\circ} 19$, de 04 de junho de 1998.

BRASIL, Ministério da Administração Federal e Reforma do Estado. A Nova política de recursos humanos. Caderno MARE da reforma do estado. Brasília, I997. c.II. $5^{2}$ p.

BRASIL. Plano Diretor da Reforma do Aparelho do Estado. Brasília: Ministério da Administração Federal e Reforma do Estado, I995.

BRASIL. Presidéncia da República. Lei 8.II2/9o. Disponível em: <http://www.planalto.gov.br/ccivil_o3/Leis/QUADRO/I99o.htm>. Acesso em: 02/o7/2009.

BRASIL. Supremo Tribunal Federal. Súmula Vinculante nº I3. Disponível em: $<$ http://www.stf.jus.br/portal/jurisprudencia/listarJurisprudencia.asp?sI=I3.NUME.\%2oE\%2OS.F LSV.\&base $=$ baseSumulasVinculantes $>$. Acesso em 26 set. 2008.

BRESSER PEREIRA, L. C. Da administração burocrática à gerencial. Revista do Serviço PúblicoRSP. Ano 47, vol.ı2O, n.I, jan./abr. 1996.

BRESSER PEREIRA, L. C. Exposição no Senado sobre a Reforma da Administração Pública. Cadernos do MARE. $\mathrm{n}^{\circ} \cdot 3$, Brasília: MARE, $\mathrm{r} 997$.

BRESSER PEREIRA, L. C. Reflexões sobre a reforma gerencial brasileira de i995. Revista do Serviço Público. ano 5, no 4, p. 5-29, out/dez. 1999.

BRESSER PEREIRA, L. C.; SPINK, P. (Org.). Reforma do Estado e Administração Pública Gerencial. $6^{\text {a }}$ ed. Rio de Janeiro: Fundação Getúlio Vargas, 2005.

BRESSER PEREIRA, L. C. Gestão do setor público. In: BRESSER PEREIRA, L. C.; SPINK, P. (Org.). Reforma do Estado e Administração Pública Gerencial. 6a ed. Rio de Janeiro: Fundação Getúlio Vargas, p. 2I-38, 2005.

CODATO, A. O departamento administrativo do Estado de São Paulo na engenharia institucional do Estado Novo. Rev. Soc. Pol., n.o9, I997, p.II3-І2I.

COSTA, Frederico L. Brasil: 200 anos de Estado; 200 anos de administração pública; 200 anos de reformas. Revista de Administração Pública - RAP. RJ, ${ }_{42}(5)$, set/out. $2008 \mathrm{a}$.

COSTA, F. L. História das reformas administrativas no Brasil: narrativas, teorizações e representações. Revista do Serviço Público - RSP. Brasília 59 (3): 277-288 Jul./Set. 20o8b.

DINIZ, E. Crise, reforma do Estado e governabilidade. Rio de Janeiro: Ed. FGV, 1998.

FAORO, R. Os donos do poder: formação do patronato político brasileiro. SP: Globo, 2000. 
FERLIE, E et al. A nova administração pública em ação. Brasília: ENAP, 1997.

FERRARI, André L. As benesses da privatização do setor elétrico brasileiro: uma promessa não cumprida? Anais... I I EnAPG, Anpad, 2004.

FERREIRA, F. Desenvolvimento e aplicação de um modelo de programa da qualidade para o serviço público. 1999. Dissertação Mestrado - Eng. de Produção, UFSC.

FLICK, U. Introdução à pesquisa qualitativa. Porto Alegre: Artmed, 2009.

FONTANELLA, B. J. B.; RICAS, J.; TURATO, E. R. Amostragem por saturação em pesquisas qualitativas em saúde: contribuições teóricas. Cad. Saúde Pública, Rio de Janeiro, v. 24, n.I, pp.I7-27, jan. 2008

.FREITAS, A.B. Traços Brasileiros para uma análise organizacional. In: MOTTA, F.; CALDAS, M.P (orgs.). Cultura Organizacional e Cultura Brasileira. SP: Atlas,I997.

FREYRE, G. Casa-Grande \& Senzala. I6 a edição. R de Janeiro: José Olympio, I973.

GUERREIRO RAMOS, A. Administração e Estratégia do Desenvolvimento. Rio de Janeiro: FGV, I966.

GUERREIRO RAMOS, A. Administração e Contexto Brasileiro. R de Janeiro: FGV, I983.

HIRSCHMAN, A. Política Econômica na América Latina. RJ: Fundo de Cultura, 1965.

HOLANDA, S. B. Raizes do Brasil. 26 a ed. Editora da Universidade, 2006.

JUNQUILHO, Gelson. S. Condutas Gerenciais e suas Raízes: uma Proposta de Análise à Luz da Teoria da Estruturação. Revista de Administração Contemporânea, Ed especial, 2003.

MACHADO-DA-SILVA, C. et. al. Institucionalização da mudança na sociedade brasileira: o papel do formalismo. In: CARVALHO, C. A.; VIEIRA, M. M. F. (Orgs.). Organizações, Instituições e Poder no Brasil. Fundação Getúlio Vargas. Rio de Janeiro: 2003.

MARINI, C. Gestão pública: o debate contemporâneo. Cadernos da Fundação Luiz Eduardo Magalhães. Salvador, n. 7, 2003.

MARTINS, H.F. A Ética do patrimonialismo e a modernização da administração pública brasileira. In: MOTTA, F.C.P; CALDAS, M.P (orgs.). Cultura Organizacional e Cultura Brasileira. São Paulo: Atlas,I997a.

MATIAS-PEREIRA, José. Administração pública comparada: uma avaliação das reformas administrativas do Brasil, EUA e União Europeia. Revista de Administração Pública - RAP. Rio de Janeiro: Vol. 42 p. 6I-82, Jan./Fev. 2008.

MOTTA, Paulo R. A modernização da administração pública brasileira nos últimos 40 anos . Revista de Administração Pública - RAP, RJ, Ed. Especial Comemorativa, p. 87-96, 2007.

NUNES, E. A Gramática Política do Brasil. Rio de Janeiro: Jorge Zahar Ed, 1997.

PAULA, Ana P P. Administração Pública Brasileira Entre o Gerencialismo e a Gestão Social. Revista de Administração de Empresas - RAE. v.45, n.I, p. 36-49, jan./mar, 2005.

PLANO DIRETOR DA REFORMA DO APARELHO DO ESTADO - PDRE. Plano Diretor. 1995. Disponível em: 
http://www.bresserpereira.org.br/Documents/MARE/PlanoDiretor/planodiretor.pdf.Acesso em: abr 2008

RIGGS, F. W. A ecologia da administração pública. Rio de Janeiro: FGV, I96I.

RIGGS, F. W. Administração nos países em desenvolvimento. Rio de Janeiro: FGV, I968.

SCHOMMER, Paula C. Gestão Pública no Brasil: Notícias do Teatro de Operações. Revista de Administração de Empresas - RAE. Vol. 43, $\mathrm{n}^{\circ} \mathrm{O} 4,2003$.

SCHWARTZMAN, S. Bases do Autoritarismo Brasileiro. RJ: Campus, 1998.

TORRES, M. D. F. Estado, democracia, administração pública no Brasil. RJ: FGV, 2004.

VASCONCELLOS, João G. M. O coronelismo nas organizações: a gênese da gerência autoritária brasileira. In: VASCONCELLOS, João G. M; DAVEL, E P B. Recursos Humanos e Subjetividade. São Paulo: Editora Vozes, 2002.

WAHRLICH, B. M. de S. Desburocratização e desestatização: novas considerações sobre as prioridades brasileiras de reforma administrativa na década de 8o. Revista de Administração Pública, v. I8, n. 4, p. 72-87, 1984.

WEBER, M. Economia e Sociedade. São Paulo: Editora Universidade de Brasília, 2004. 